\title{
Spectroscopic Diagnostics of Laser Plasma Plume of Aluminum
}

\author{
Mikhailo Chuchman, Livia Mesarosh, Aleksandr Shuaibov
}

Physical Phaculty, Uzhgorod National University, Uzhgorod, Ukraine

Email address:

mchuchman@ukr.net (M. Chuchman), liviamesarosh@gmail.com (L. Mesarosh), shuaibov@i.ua (A. Shuaibov)

\section{To cite this article:}

Mikhailo Chuchman, Livia Mesarosh, Aleksandr Shuaibov. Spectroscopic Diagnostics of Laser Plasma Plume of Aluminum. Optics. Vol. 4, No. 5, 2015, pp. 31-36. doi: 10.11648/j.optics.20150405.11

\begin{abstract}
The emission of aluminum Al laser ablated plasma has been investigated in the 200-600 nm spectral range. The most intensive spectral lines were 308.2; 309.3; 394.4 and $396.2 \mathrm{~nm} \mathrm{Al} \mathrm{I.} \mathrm{The} \mathrm{highest} \mathrm{levels} \mathrm{of} \mathrm{neutral} \mathrm{atoms,} \mathrm{responsible} \mathrm{for}$ the detected spectral lines, correspond to the two-electron excitation with 8.3-9.06 eV energy. The time average value of electron temperature on the 1 and $7 \mathrm{~mm}$ distances from the target was calculated. It is $0.43 \mathrm{eV}$ for $1 \mathrm{~mm}$ and $0.51 \mathrm{eV}$ for $7 \mathrm{~mm}$ distance from the target. The experimentally obtained time of recombination ( $29 \mathrm{~ns}$ ) have been used to extract the electron number density at $1 \mathrm{~mm}$ from the target which is $9.4 \times 1015 \mathrm{~cm}^{-3}$. The time-resolved emission of atomic spectral lines at $1 \mathrm{~mm}$ distance from the target was studied. The maximums of aluminum spectral lines emission have appeared in times of 8-20 ns, which correspond to atom velocities of $(0.05-0.13) \times 10^{6} \mathrm{~m} / \mathrm{s}$.
\end{abstract}

Keywords: Aluminum Laser Plasma, Emission Spectrum, Laser Plume, Oscillograms of Spectral Lines

\section{Introduction}

Pulsed laser ablation plasmas produced by high power laser radiation near a solid target have numerous applications $[1,2]$. These include deposition of thin layers, vaporization of sample material for spectrochemical analysis, formation of atomic, molecular and cluster beams. For optimization of these applications it is of great importance to understand the basic physical and chemical processes determining the plasma composition at various stages of its evolution.

Optical spectroscopy provides information about the spatial and temporal evolution of transient species produced by the laser-target interaction, such as excited atoms, ions or molecules [3]. Information about the laser-target and laserplasma interaction can be obtained by observing and studying volume elements near the target at early stages of plasma expansion. The plasma species reactivity, which is essential for a thin film formation, is studied at long distances from the target. Better insights into the dynamics of the ablated material can help to understand and eventually control the ablation process. In the present work, we have studied the spatial evolution of the aluminum plasma by emission spectroscopy method.

The study of the spectral composition of radiation of aluminum laser plasma is also presented in [4]. The duration of laser pulses was $5 \mathrm{~ns}$ with pulse repetition rate of $10 \mathrm{~Hz}$ and power density of $5.5 \times 10^{10} \mathrm{~W} / \mathrm{sm}^{2}$ at the wavelength of $1064 \mathrm{~nm}$. A spectrum of aluminum laser plasma was registered from areas of from 0 to $5 \mathrm{~mm}$ from the target. As shown [4] in the spectrum neutral aluminum lines were present at wavelengths of $226.90 \mathrm{~nm}, 256.79 \mathrm{~nm}, 257.51 \mathrm{~nm}$, $265.24 \mathrm{~nm}, 266.04 \mathrm{~nm}, 308.21 \mathrm{~nm}, 309.28 \mathrm{~nm}, 336.70 \mathrm{~nm}$, $337.31 \mathrm{~nm}, 394.40 \mathrm{~nm}, 396.15 \mathrm{~nm}, 669.60 \mathrm{~nm}$. Singly ionized aluminum lines were observed at $281.61 \mathrm{~nm}, 358.65$ $\mathrm{nm}, 466.3 \mathrm{~nm}$. The doubly ionized aluminum lines are $360.19 \mathrm{~nm}, 361.23 \mathrm{~nm}, 370.20 \mathrm{~nm}, 371.31 \mathrm{~nm}$.

In [5] plasma of aluminum was created by $\mathrm{Nd}$ : YAG laser $\left(1064 \mathrm{~nm}, 10 \mathrm{~ns}, 5 \times 10^{8} \mathrm{~W} / \mathrm{cm}^{2}\right)$ at the distance of $0.5 \mathrm{~mm}$ from a target with the air pressure of $0.133 \mathrm{~Pa}$. The measured parameters of plasma were concentration of electrons to the time moment of $2 \mu \mathrm{s}$ and temperature of electrons to $1.2 \mu \mathrm{s}$. Using Nd: YAG laser $\left(1064 \mathrm{~nm}, 8 \mathrm{~ns}, 4 \times 10^{10} \mathrm{~W} / \mathrm{cm}^{2}\right)$ [6], aluminum plasma was studied in a vacuum $\left(1.33 \times 10^{-3} \mathrm{~Pa}\right)$ where it was shown that the of temperature of electrons and the concentration of electrons changes at 1-12 mm distance from a target. In general, the plasma temperature and electron number density exhibit the specific of the plasma expansion during the different time intervals.

In [4] the spatial distribution of parameters of aluminum plasma was studied. Plasma was generated in air by the action of neodymium laser. The temperature of electrons near 
the target surface was $0.83 \mathrm{eV}$ and decreases to $0.66 \mathrm{eV}$ at the distance of $5 \mathrm{~mm}$ from the target. The electron number density close to the target is $1.3 \times 10^{18} \mathrm{~cm}^{-3}$ and decreases to $4.2 \times 10^{17} \mathrm{~cm}^{-3}$ at $5 \mathrm{~mm}$ from the target. With the change of laser power density within the limits of $1.3-7.6 \times 10^{10} \mathrm{~W} / \mathrm{cm}^{2}$ the temperature of electrons grows from 0.61 to $1.01 \mathrm{eV}$, and the concentration of electrons changes from $4.2 \times 10^{17}$ to $7.6 \times 10^{18} \mathrm{~cm}^{-3}$.

In [7] the change of speed of laser plasma of aluminum is analysed at varying the pressure from $10^{-2}$ to $133.3 \times 10^{2} \mathrm{~Pa}$. Frequency doubled $\mathrm{Nd}$ was used: YAG laser $(523 \mathrm{~nm}, 8 \mathrm{~ns}$, $3 \times 10^{9} \mathrm{~W} / \mathrm{cm}^{2}$ ). By photoimaging of plasma it was shown that a transition from the mode of free expansion to the mode of formation of shock wave takes place in the range of pressures from 1.333 to $133.3 \mathrm{~Pa}$. At pressures smaller than $133.3 \mathrm{~Pa}$ plasma moves to the distance of $5 \mathrm{~mm}$ with a constant speed. Whereupon the speed slowly decreased, as shown in [8] it can be described by the shock wave model. Spatially, the constant velocity of plasma at $40-80 \mathrm{~ns}$ is observed from 0.5 to $1.5 \mathrm{~mm}$ at pressure $1.3 \times 10^{4} \mathrm{~Pa}$. At pressures higher than 133.3 Pa, the change of velocity is more complicated and the temporal dependence of position in plasma front is described by a transitional model.

Oscillograms of radiation of atoms and singly charged ions [7] allowed to determine the rates of motion of different constituents of plasma at a pressure of $20 \mathrm{~Pa}$. In accordance with the oscillograms of radiation of aluminum atoms and ions, two peaks appear. The first peak moves with the constant velocity while the second one does not change its velocity till time $200 \mathrm{~ns}$ and distances of $4 \mathrm{~mm}$.

As shown in [9] the plasma velocity changes with the change of distance from the target from 0.5 to $2 \mathrm{~mm}$ at the atmospheric pressure and at the laser power density of $9.5 \times 10^{9} \mathrm{~W} / \mathrm{cm}^{2}(1064 \mathrm{~nm}, 10 \mathrm{~ns})$.

In [6] the value of the velocity propagation of plasma obtained from images of laser plume was $0.066 \times 10^{6} \mathrm{~m} / \mathrm{s}$. From the oscillogramms of emission intensity it was found that the maximum expansion velocities of $\mathrm{Al}^{2+}, \mathrm{Al}^{1+}$, and $\mathrm{Al}$ are $0.054 \times 10^{6} \mathrm{~m} / \mathrm{s}, 0.031 \times 10^{6} \mathrm{~m} / \mathrm{s}$, and $0.021 \times 10^{6} \mathrm{~m} / \mathrm{s}$, respectively.

\section{Experimental Setup}

Plasma was produced by focusing of a $\mathrm{Nd}$ : YAG laser radiation $(1.06 \mu \mathrm{m}, 20 \mathrm{~ns}, 12 \mathrm{~Hz})$ on the surface of the aluminum target. The laser radiation was focused on the target surface into a spot size of $0.45 \mathrm{~mm}$ in diameter. A specific power on the target surface was $4 \times 10^{8} \mathrm{~W} / \mathrm{cm}^{2}$. The extra pure grade aluminum target was placed in the vacuum chamber under a residual gas pressure of $7 \mathrm{~Pa}$. Plasma emission was analysed in the spectral area of 200-600 nm and was collected from 0.3 -mm-thick laser-plume cross sections situated parallel to the target surface and located at distances of 1 and $7 \mathrm{~mm}$ from it. The experimental setup is shown in the fig. 1 .

Emission intensities were corrected for the detector + monochromator spectral response. The measurement system consists of an MDR-2 monochromator (1200 grooves $\mathrm{mm}^{-1}$ ), FEU-106 photomultiplier and a KSP-4 recorder. For measurements of the time dependencies of the line intensities the radiation from the output of the monochromator was then applied to an ELU14-FS linear photomultiplier, the electric signal from which was taken to a 6LOR-04 fast oscilloscope. The temporal resolution is $2 \mathrm{~ns}$. The intensity was measured with accuracy of not less than $10 \%$. The spectra were interpreted using the data from Refs. [10, 11]. Knowing the spectral sensitivity of the photomultiplier enables us to compare the relative intensities of the spectral lines and calculate some parameters of the laser plasma.

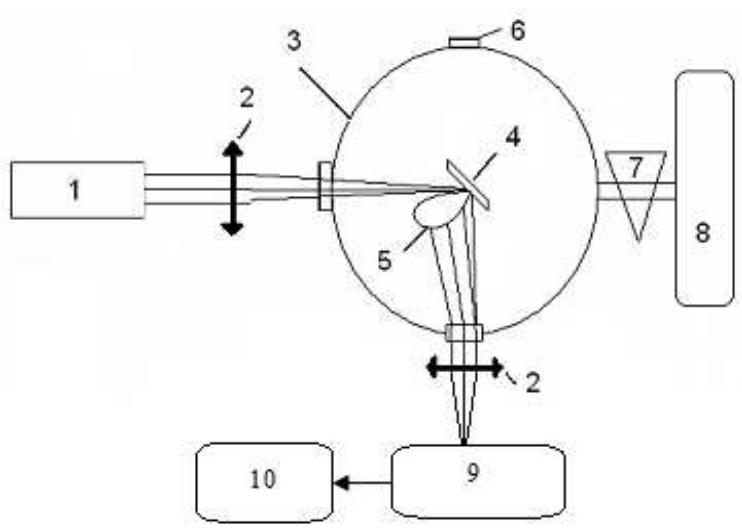

Figure 1. Experimental setup: 1 - Nd: YAG laser, 2 - focusing lens, 3 vacuum chamber, 4 - aluminum target, 5 - plasma plume, 6 - quartz window, 7 - vacuum pump, 8 - valve of vacuum pump, 9 - MDR-2 monochromator, 10 - the measurement system: FEU-106 photomultiplier and a KSP-4 recorder or ELU14-FS linear photomultiplier and 6LOR-04 fast oscilloscope.

Measurements of the time dependencies of the spectral line intensities allows to determine the plasma velocity by monitoring the propagation of the intensity maximum from the target surface. The speed was determined at time $(t)$ by appearance of radiation maximum at fixed distance $(s)$ from target: $v=s / t$. The time of ion recombination has been calculated with the help of the formula [12]:

$$
t_{r}=\frac{\Delta t}{\Delta \ln \left(I / I_{\max }\right)}
$$

where $t_{r}$ is the ion recombination time and $\Delta \ln \left(I / I_{\max }\right)$ is the change in the logarithm of the normalized line intensity within the time interval $\Delta t$ [12]. The time-average relative line intensities and spectroscopic constants of these lines [10, 11] make it possible to calculate the populations of the excited atomic states using [13]:

$$
N_{m}=I_{m i} \lambda_{m i} / A_{m i}
$$

where $N_{m}$ is the population of the $m$ th excited state, $I_{m i}$ is the intensity of the spectral line corresponding to the transition from the $m$ th to the $i$ th energy level, $A_{m i}$ is the transition probability, and $\lambda_{m i}$ is the wavelength of the spectral line. The electron temperature can be determined from the slope of the energy distribution logarithm of the populations of the excited atomic states, $\ln (N / g$ ) (where $g$ is the statistical 
weight) [13]:

$$
T_{e}=\Delta E / \Delta \ln (N / g) .
$$

From the known values of $T_{e}$ and $t_{r}$, one can estimate the electron density $n_{e}[12]$ :

$$
n_{e}=\left(8,75 \times 10^{-27} z^{3} t_{r} T_{e}^{-9 / 2}\right)^{-1 / 2}
$$

where $z$ is the charge number of the recombining ions.

\section{Results and Discussion}

Spectra of the aluminum laser plume were recorded at 1 and $7 \mathrm{~mm}$ distances from the target (Fig. 2). Table 1 shows the data for the most intensive spectral lines of aluminum plasma radiation which are the wavelength $(\lambda)$, the relative intensity of radiation at $1 \mathrm{~mm}$ from the target $\left(I_{l}\right)$ and at 7 $\mathrm{mm}$ from the target $\left(I_{7}\right)$, electronic configuration, terms and upper energy state, and probabilities of transitions $(A)$. At a distance of $1 \mathrm{~mm}$ from the target the most intense atomic spectral lines were observed at wavelengths 308.2, 309.3, $394.4,396.2 \mathrm{~nm}$. Emission of ions was recorded at wavelengths of $281.6,358.7,466.3 \mathrm{~nm}$ with the intensity of each of them to be more than $10 \%$ of the intensity of the most intensive spectral line of an aluminum atoms (308.2 $\mathrm{nm})$. Ionization composition of the plasma indicates the presence of single- and double-charged ions.


Figure 2. The emission spectrum of aluminum recorded at two distances from the target which consists of the spectral lines originated from transitions in the neutral, singly and double ionized aluminum.

\begin{tabular}{|c|c|c|c|c|c|c|c|c|}
\hline$\lambda, \mathrm{nm}$ & $I_{1}$, a.u. & $I_{7}$, a.u. & Atom, ion & $A, \mathrm{~s}^{-1}$ & $E_{m}, \mathbf{e V}$ & Config. Upper & Transition & $J_{i}-J_{m}$ \\
\hline 245.9 & 0.07 & - & II & - & 18.1155 & $3 \mathrm{~s} 10 \mathrm{~s}$ & ${ }^{3} \mathrm{P}^{\circ}-{ }_{-}^{3} \mathrm{~S}$ & $2-1$ \\
\hline 257.5 & 0.10 & 0.11 & $\mathrm{I}$ & $2.8 \mathrm{E} 7$ & 4.8272 & $3 \mathrm{~s} 2(1 \mathrm{~S}) \mathrm{nd}$ & ${ }^{2} \mathrm{P}^{\circ}-{ }^{2} \mathrm{D}$ & $3 / 2-5 / 2$ \\
\hline 263.7 & 0.09 & 0.05 & II & - & 16.5457 & $3 \mathrm{~s} 5 \mathrm{f}$ & ${ }^{3} \mathrm{D}-{ }^{3} \mathrm{~F}^{\circ}$ & $3-4$ \\
\hline 266.9 & 0.08 & 0.07 & II & - & 4.6436 & $3 s 3 p$ & ${ }^{1} \mathrm{~S}-{ }^{3} \mathrm{P}^{\circ}$ & $0-1$ \\
\hline 281.6 & 0.14 & - & II & $3.83 \mathrm{E} 8$ & 11.8219 & $3 s 4 s$ & ${ }^{1} \mathrm{P}^{\circ}-{ }_{-}^{1} \mathrm{~S}$ & $1-0$ \\
\hline 293.6 & - & 0.03 & I & - & 9.0482 & $3 \mathrm{~s} 3 \mathrm{p}\left(3 \mathrm{P}^{\circ}\right) 3 \mathrm{~d}$ & ${ }^{2} \mathrm{D}-{ }^{2} \mathrm{~F}^{\circ}$ & $3 / 2-5 / 2$ \\
\hline 296.1 & 0.04 & - & I & - & 9.0482 & $3 \mathrm{~s} 3 \mathrm{p}\left(3 \mathrm{P}^{\circ}\right) 3 \mathrm{~d}$ & ${ }^{2} \mathrm{D}-{ }^{2} \mathrm{~F}^{\circ}$ & $3 / 2-5 / 2$ \\
\hline 305.7 & 0.16 & - & I & - & 7.6676 & $3 \mathrm{~s} 3 \mathrm{p}\left(3 \mathrm{P}^{\circ}\right) 4 \mathrm{~s}$ & ${ }^{4} \mathrm{P}_{-}^{4} \mathrm{P}^{\circ}$ & $5 / 2-5 / 2$ \\
\hline 308.2 & 1.37 & 2.79 & I & $6.3 \mathrm{E} 7$ & 4.0214 & $3 \mathrm{~s} 23 \mathrm{~d}$ & ${ }^{2} \mathrm{P}_{-}^{\circ}{ }^{2} \mathrm{D}$ & $1 / 2-3 / 2$ \\
\hline 309.3 & 0.76 & 3.47 & I & $7.4 \mathrm{E} 7$ & 4.0216 & $3 \mathrm{~s} 23 \mathrm{~d}$ & ${ }^{2} \mathrm{P}^{\circ}{ }^{2} \mathrm{D}$ & $3 / 2-5 / 2$ \\
\hline 313.5 & 0.09 & - & II & - & 17.2090 & $3 \mathrm{~s} 7 \mathrm{~s}$ & ${ }^{1} \mathrm{P}^{\circ}-{ }_{-}^{1} \mathrm{~S}$ & $1-0$ \\
\hline 318.4 & 0.08 & - & III & - & 26.0205 & $2 \mathrm{p} 68 \mathrm{~s}$ & ${ }^{2} \mathrm{P}^{\circ}-{ }^{2} \mathrm{~S}$ & $3 / 2-1 / 2$ \\
\hline 324.1 & - & 0.03 & I & - & 9.0604 & $3 \mathrm{~s} 3 \mathrm{p}\left(3 \mathrm{P}^{\circ}\right) 3 \mathrm{~d}$ & ${ }^{2} \mathrm{D}-{ }^{2} \mathrm{~F}^{\circ}$ & $5 / 2-7 / 2$ \\
\hline 327.6 & 0.04 & - & II & - & 15.6057 & $3 \mathrm{~s} 5 \mathrm{p}$ & ${ }^{1} \mathrm{~S}-{ }^{1} \mathrm{P}^{\circ}$ & $0-1$ \\
\hline 355.2 & - & 0.05 & II & - & 18.5516 & $3 \mathrm{~s} 14 \mathrm{f}$ & ${ }^{3} \mathrm{D}-{ }^{3} \mathrm{~F}^{\circ}$ & $3-4$ \\
\hline 358.7 & 0.17 & 0.03 & II & - & 15.3025 & $3 s 4 f$ & ${ }^{3} \mathrm{D}-{ }^{3} \mathrm{~F}^{\circ}$ & $1-4$ \\
\hline 365.5 & 0.04 & - & II & $6.9 \mathrm{E} 6$ & 16.4679 & $3 \mathrm{~s} 5 \mathrm{~d}$ & ${ }^{3} \mathrm{P}_{-}^{\circ}{ }^{3} \mathrm{D}$ & $2-2$ \\
\hline 371.3 & 0.04 & - & III & 2.27E8 & 21.1563 & $2 \mathrm{p} 65 \mathrm{~s}$ & ${ }^{2} \mathrm{P}^{\circ}-{ }_{-}^{2} \mathrm{~S}$ & $3 / 2-1 / 2$ \\
\hline 377.1 & - & 0.03 & II & - & 18.1763 & $3 \mathrm{~s} 10 \mathrm{p}$ & ${ }^{3} \mathrm{~S}-{ }^{3} \mathrm{P}^{\circ}$ & $3-3$ \\
\hline 394.4 & 1.28 & 0.86 & I & 4.93E7 & 3.1427 & $3 \mathrm{~s} 24 \mathrm{~s}$ & ${ }^{2} \mathrm{P}^{\circ}-{ }^{2} \mathrm{~S}$ & $1 / 2-1 / 2$ \\
\hline 396.2 & 1.32 & 0.68 & I & $9.8 \mathrm{E} 7$ & 3.1427 & $3 \mathrm{~s} 24 \mathrm{~s}$ & ${ }^{2} \mathrm{P}^{\circ}-{ }_{-}^{2} \mathrm{~S}$ & $3 / 2-1 / 2$ \\
\hline 408.3 & 0.04 & - & III & - & 25.1590 & $2 \mathrm{p} 67 \mathrm{~s}$ & ${ }^{2} \mathrm{P}_{-}{ }_{-}^{2} \mathrm{~S}$ & $1 / 2-1 / 2$ \\
\hline 452.9 & 0.08 & 0.04 & III & $2.54 \mathrm{E} 8$ & 20.5548 & $2 \mathrm{p} 64 \mathrm{~d}$ & ${ }^{2} \mathrm{P}^{\circ}-{ }^{2} \mathrm{D}$ & $3 / 2-5 / 2$ \\
\hline 466.3 & 0.17 & - & II & $5.3 \mathrm{E} 7$ & 13.2564 & $3 s 4 p$ & ${ }^{1} \mathrm{D}-{ }^{1} \mathrm{P}^{\circ}$ & $2-1$ \\
\hline
\end{tabular}

Table 1. Intensities and spectroscopic data of aluminum emission lines. 
By applying the method of mass-spectrometry for plasma formed under the action of neodymium laser radiation with the power density of $5 \times 10^{10} \mathrm{~W} / \mathrm{cm}^{2}$ on an aluminum target, it was found that in the plasma $\mathrm{Al}^{+}, \mathrm{Al}^{2+}, \mathrm{Al}^{3+}$, and $\mathrm{Al}^{4+}$ are presented. In comparison with single-charged ions the numbers of double-charged, triple-charged and fourfoldcharged ions are twice, an order of magnitude, and two orders of magnitude respectively smaller [14].

At the distance of $7 \mathrm{~mm}$ from a target only four spectral atomic lines most clearly shows up, namely 308.2; 309.3; $394.4 ; 396.2 \mathrm{~nm}$. The intensities of all other spectral lines are $\leq 3 \%$ of the intensity of the most intensive spectral line of aluminum atoms $(309.3 \mathrm{~nm})$.

In the spectrum, singly charged and double-charged ions are observed, though their intensities on the average are $\sim 7$ times smaller than for atoms, and it drastically decreasing with the increase of the distance from the target.

Radiation on wavelengths of 308.2 and $309.3 \mathrm{~nm}$ at the distance $7 \mathrm{~mm}$ from the target is more intensive than at distance of $1 \mathrm{~mm}$. With the increase of distance from the target the number of spectral lines that radiation appears at transitions from the displaced states increases. The number of spectral lines, which causes the radiation of the ionized particles, diminishes considerably, however the intensity increases for spectral lines of singly charged ions with the upper energy states within the limits of 17-19 eV. For doublecharged ions the spectral lines, which are correspond to transitions from the high-excited states disappears completely

Shaikh et al [4] investigated the Al target as well as the plasma's spectral emission at higher power density. In the spectrum, neutral, singly ionized and doubly ionized aluminum lines were present.

For aluminum laser plasma, which was generated by neodymium laser (1064 nm, $1 \mathrm{~J}, 15 \mathrm{~ns})$, the authors [15] showed that, with the increase of pressure from $13.3 \mathrm{~Pa}$ to atmospheric pressure, the intensity of radiation increases by 22 times, whereas the temperature increased by 19 times and the concentration of particles in plasma increased by 85 times.

The position of the bottleneck of the recombination stream of ions corresponds to energetic level with the highest energy, from which we can observe the radiation of particles with the one time smaller charge. For the atoms of aluminum on 1 $\mathrm{mm}$ from the target correspond energy levels of $E=9.06 \mathrm{eV}$ and on $7 \mathrm{~mm}$ from the target it corresponds to the $8.3 \mathrm{eV}$. These energy levels are displaced and correspond to the energies higher than the potential of ionization of aluminum atoms, they appear due to two-electronic excitation. In the case of singly charged ions this levels are $E=18.12 \mathrm{eV}$ and $18.55 \mathrm{eV}$, and for double-charged ions $E=26.02 \mathrm{eV}$ and $20.55 \mathrm{eV}$ for distances of 1 and $7 \mathrm{~mm}$ from the target respectively. For the singly charged ion, the difference between the energy position of bottleneck of recombination stream and ionization energy of atom is $0.7 \mathrm{eV}$ and $0.27 \mathrm{eV}$ at 1 and $7 \mathrm{~mm}$ from the target respectively. It means that the level of electronic temperature remains within the limits of a tenth part of electronvolt. The same data for double-charged ions at the distance of $1 \mathrm{~mm}$ from a target imply that the electrons temperature is about $2 \mathrm{eV}$. Obviously, due to the different spatial position of ions with different charge, these data provide the overall picture of the temperature of electrons in the different spatial areas of plasma. In particular, the energy spectrums of ions with different charge have also indicated it [16]. It is also necessary to remark that $\mathrm{Al}^{3+}$ in plasma at a distance of $7 \mathrm{~mm}$ from the target formed through the recombination processes remain in very insubstantial quantity and they stop determining the formation of the higher excited states of double-charged ions.

A typical view of time averaged value of the Boltzmann distribution for atomic components of laser plasma is presented in fig. 3, which confirms the presence of a local thermodynamic equilibrium and the capability of our methods. Spatial stratification of plasma components with different charge, and rapid recombination of ions with charge $>1$ results in the increased formation of the higher excited states of singly charged ions which manifest in inversion. The results show that the ratio of the number of atoms in a ground-state to the singly charged ion number near the edge of ionization is $\sim 5 \times 10^{3}$. The ratio of maximal values of population of the excited states of atoms and singly charged ions to double-charged ones is $1: 7 \times 10^{-2}: 4 \times 10^{-3}$.
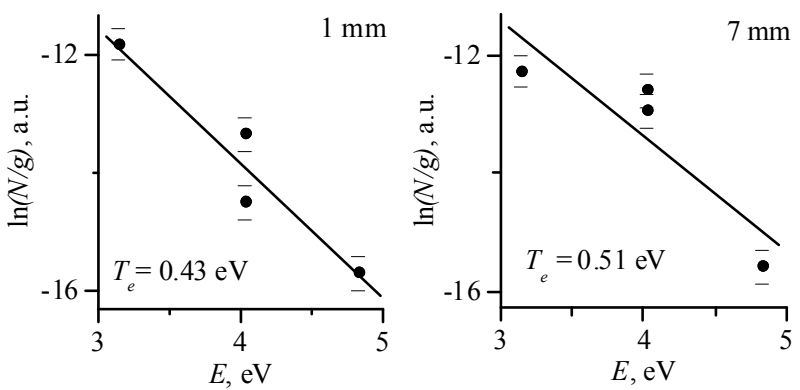

Figure 3. Time averaged value of the electron temperature at $1 \mathrm{~mm}$ and 7 mm from the target.

The time-averaged values of the electronic temperature of plasma are $0.43 \mathrm{eV}$ at $1 \mathrm{~mm}$ from the target and $0.51 \mathrm{eV}$ for 7 $\mathrm{mm}$ respectively.

The top and bottom limits of distances at which a shock wave is formed in accordance with the calculations [11] is $0.55-1.1 \mathrm{~cm}$. Thus the change of character of plasma expansion has been observed experimentally. Fig. 4 indicates the formation of shock wave with compression of the plasma and temperature increase after $0.55 \mathrm{~cm}$ distance. This agrees with the data on the temperature shows in Fig. 3.

Several groups have determined temperature and electron number density at the early stages of plasma plume development. Tarasenko et al [5] calculated parameters of plasma $\mathrm{n}_{\mathrm{e}}=\left(1.4 \times 10^{18}-1.5 \times 10^{17}\right) \mathrm{cm}^{-3}$ and $\mathrm{T}_{\mathrm{e}}=(1.6-0.8)$ $\mathrm{eV}$. In [6] change limits of electrons temperature is $2.8-0.9$ $\mathrm{eV}$ and for concentration of electrons is $9.1-5 \times 10^{17} \mathrm{~cm}^{-3}$. In Refs. [4] temperature of electrons grows from 0.61 to $1.01 \mathrm{eV}$, and the concentration of electrons changes from $4.2 \times 10^{17}$ to $7.6 \times 10^{18} \mathrm{~cm}^{-3}$. 


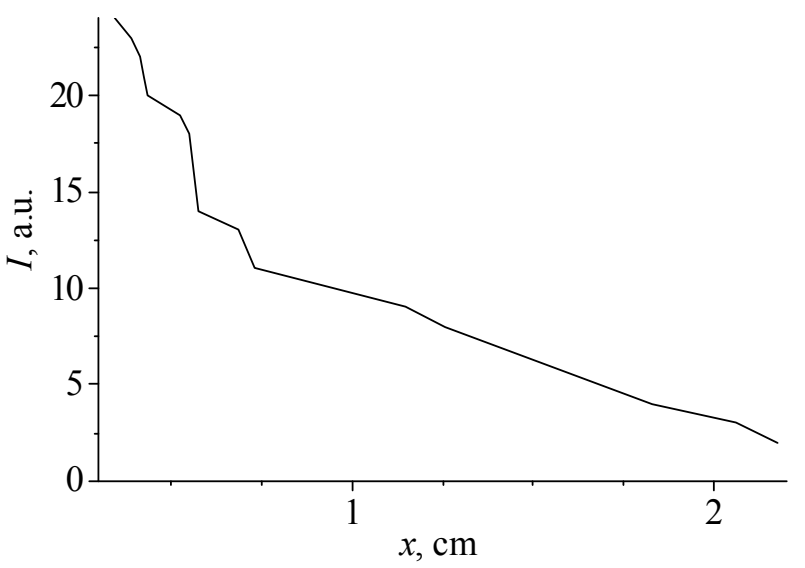

Figure 4. Dependence of the integral of the wavelength intensity of radiation at the central area of aluminum laser plasma plume on the distance from the target at the ambient gas pressure of $7 \mathrm{~Pa}$.

Our results are in good agreement with published data in [3] and can be useful in optimizing conditions for aluminum film lithography and deposition.

Based on oscillogram intensities of spectral line of 308.2 $\mathrm{nm} \mathrm{Al} \mathrm{I} \mathrm{(Fig.} \mathrm{5)} \mathrm{the} \mathrm{dependence} \mathrm{of} \ln \left(I / I_{\max }\right)$ on time may be derived, from which the value of recombination time of singly charged ions is obtained. The time of recombination is $29 \mathrm{~ns}$ for the distance of $1 \mathrm{~mm}$ from a target in the range of 20-50 ns. Using the level of the electron temperature and recombination time, the time averaged value of the concentration of electrons was calculated which is $n_{e}=$ $9.4 \times 10^{15} \mathrm{~cm}^{-3}$.

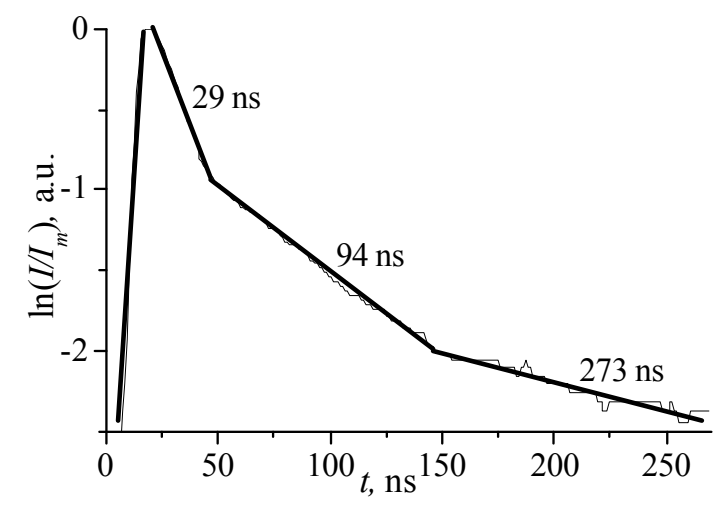

Figure. 5. The dependence of $\ln \left(I / I_{\max }\right)$ on time for $308.2 \mathrm{~nm}$ atomic spectral line of aluminum at the distance of $1 \mathrm{~mm}$ from the target.

Thus, the fastest decreasing of plasma parameters takes place in a spatial area to $2 \mathrm{~mm}$ in times of about $100 \mathrm{~ns}$ as the increase of gas pressure in a vacuum chamber is more apparent $[3,7,8]$. Over time, the concentration of particles is reduced and all processes are slowed down. Thus recombination time decreases by step way: $29-94-273 \mathrm{~ns}$ (see fig. 5).

Figure 6 shows the time of flight dependencies for intensity of spectral lines at $1 \mathrm{~mm}$ distance from the target. The duration of radiation is $>200 \mathrm{~ns}$. The maxima appear in the time interval of $8-20 \mathrm{~ns}$. The emission on the $394.4 \mathrm{~nm}$ wavelength is $\sim 4$ times less intense than at $308.2 \mathrm{~nm}$, however the duration of radiation is three times longer. The propagation speed of the plasma determined by the position of maxima of intensity on oscillograms at the distance of 1 $\mathrm{mm}$ from a target is $(0.13-0.05) \times 10^{6} \mathrm{~m} / \mathrm{s}$. According to Refs. [7] the velocities of atoms in the first maximum is $0.065 \times 10^{6}$ $\mathrm{m} / \mathrm{s}$, and for the ions it is $0.076 \times 10^{6} \mathrm{~m} / \mathrm{s}$. As shown in Refs. [9] the plasma velocity changes from $0.25 \times 10^{6}$ to $0.04 \times 10^{6}$ $\mathrm{m} / \mathrm{s}$.

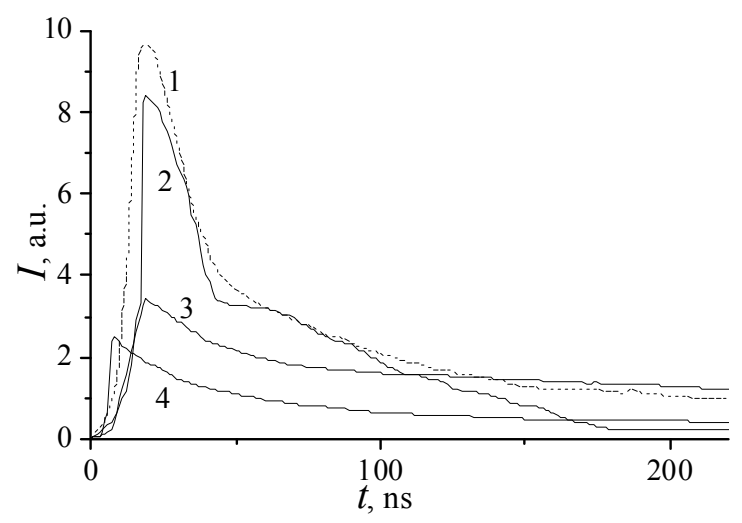

Figure. 6. Oscillograms of intensity of aluminum atomic spectral lines at a distance of $1 \mathrm{~mm}$ from the target: 1-308.2, 2-309.3; 3-396.2; 4-394.4 $\mathrm{nm}$.

Judging by the obtained data we can see that in the different spatial areas of plasma the ratio of concentrations is varied not only for particles with different charges but also for atoms in the different excited states. It is also necessary to note that, in the different time intervals of existence of plasma, the specific features of plasma propagation are observed which correspond to the change of propagation velocity, to the distribution of intensity, temperature and electron concentration. The realization of recombination processes in different spatial intervals depends on the pressure of the ambient gas and the power of laser radiation.

\section{Conclusions}

In this article, the spectra of aluminum emission at the distances of 1 and $7 \mathrm{~mm}$ from the target are analyzed at the threshold conditions of a laser plume formation $\left(4 \times 10^{8}\right.$ $\left.\mathrm{W} / \mathrm{cm}^{2}, 7 \mathrm{~Pa}\right)$. These conditions are optimal for film deposition and data can be used to applications points as well as for spectroscopic diagnostics of laser plasma plume of aluminum.

The most intensive spectral lines of erosive plasma plume of aluminum are $308.2 ; 309.3 ; 394.4 ; 396.2 \mathrm{~nm} \mathrm{Al} \mathrm{I}$ and 281.6; 358.7; $466.3 \mathrm{~nm}$ Al II.

The obtained experimentally position of the bottleneck of the recombination stream of the aluminum atoms after recombination of singly-charged ions is equal to the energy levels of $E=9.06 \mathrm{eV}$ and $8.3 \mathrm{eV}$ at the distance of 1 and 7 $\mathrm{mm}$ from the target.

The value of electronic temperature of plasma is $0.43 \mathrm{eV}$ at the distance of $1 \mathrm{~mm}$ from the target and $0.51 \mathrm{eV}$ for $7 \mathrm{~mm}$. The time averaged value of the concentration of electrons at the distance of $1 \mathrm{~mm}$ from a target is $n_{e}=9.4 \times 10^{15} \mathrm{~cm}^{-3}$ for 
the recombination time of 29 ns.

The duration of radiation of laser plasma of aluminum was found to be about 200 ns. The most intensive maximum is observed at $20 \mathrm{~ns}$ and the appearance of three maximums was noticed at the time interval of 18-20 ns, the least intensive is observed on $8 \mathrm{~ns}$. The distribution of velocity of atoms in laser plasma of aluminum is in $(0.05-0.13) \times 10^{6} \mathrm{~m} / \mathrm{s}$ range.

\section{References}

[1] F. Claeyssens, S. J. Henley, M. N. Ashfold, "Comparison of the ablation plumes arising from ArF laser ablation of graphite, silicon, copper, and aluminum in vacuum," J. Appl. Phys., vol. 94, no. 4, pp. 2203-2211, 2003.

[2] L. K. Ang, Y. Y. Lau, R. M. Gilgenbach, "Surface instability of multipulse laser ablation on metalic target," J. Appl. Phys., vol. 83, no 8. pp. 4466-4471, 1998.

[3] S. Dadras, M. J. Torkamany, J. Sabbaghzadeh, "Characterization and comparison of iron and aluminum laser ablation with time-integrated emission spectroscopy of induced plasma," J. Phys. D: Appl. Phys., vol. 41, 225202. (7pp), 2008.

[4] N. M. Shaikh, S. Hafeez, B. Rashid, et al., "Spectroscopic studies of laser induced aluminum plasma using fundamental, second and third harmonics of a Nd: YAG laser", Eur. Phys. J. D., vol. 44, pp. 371-377, 2007.

[5] N. V. Tarasenko, "Laser-Induced Fluorescence and TimeResolved Emission Spectroscopy of Laser Ablation Plasma," Plasma Fusion and Plasma Physics, vol. 22, pp. 1647-1649, 1998.

[6] S. S. Harilal, M. S. Tillack, B. O'Shay, et al., "Confinement and dynamics of LPP expanding across a magnetic field," Physical Review E., vol. 69, 026413. (11pp), 2004.
[7] S. S. Harilal, C. V. Bindhu, M. S. Tillack, "Internal structure \& expansion dynamics of laser ablation plumes into ambient gases," J. Appl. Phys., vol. 93, pp. 2380-2399, 2003.

[8] T. Itina, J. Hermann, P. Delaporte, et al., "Laser-generated plasma plume expansion: Combined continuous-microscopic modeling," Physical Review E., vol. 66, 066406, (12 pp), 2002.

[9] Xiangtai Wang, Baoyuan Man, "Laser-Induced Plasma on the Surface of Aluminum Target in Air," Journal of the Korean Physical Society, vol. 32, pp. 373-375, 1998.

[10] P. L. Smith, C. Heise, J. R. Esmond, et al., (1995). Atomic Spectral Line Database from CD-ROM, Cambridge, Smithsonian Astrophysical Observatory. Available: http://cfawww.harvard.edu/amp.

[11] A. N. Zaedel, V. K. Prokofjev, S. M. Raiskij, et al., Tables of Spectral Lines, Moscow, Nauka, 1962, 782 p.

[12] L. T. Sukhov, Laser Spectral Analysis, Novosibirsk, Nauka, 1990. $143 \mathrm{p}$.

[13] Plasmas Diagnostics, W. Lochte-Holtgreven Ed., New York, American Elsevier, pp. 552, 1968.

[14] R. T. Khaydarov, V. B. Terent'ev,. T. V. Akramov, et al., "Methods for improving characteristics of laser source of ions", Plasma Physics Reports, vol. 35, pp. 847-851, 2009.

[15] O. A. Bukin, E. N. Bol'shakova, E. A. Sviridenkov, et al., "Shift of the emission lines of aluminum in a laser plasma generated on the surface of a solid target in the atmosphere," Technical Physics Letters, vol. 23, no. 12, pp. 913-920, 1997.

[16] M. P. Chuchman, A. K. Suaibov, L. V. Mesarosh, "Spatial and Emission Characteristics of Aluminum Laser Torch plasma, High Temperature,” vol. 49, pp. 453 - 463, 2011. 